\title{
O DIMINUTIVO E SUAS DEMANDAS
}

(Diminutives and their demands)

Leda BISOL

(PUCRS, CNPq)

Resumo: Este estudo revê as diferentes interpretações e análises do diminutivo mais produtivo em português e reaviva a visão de Soares Barbosa (1787), obliterada pela maioria dos estudos do século passado. Tomando seu ponto de vista como referência, a hipótese que guia esta análise, fundamentada na Teoria da Otimidade, é ser -inho o morfema de diminutivo e/z/ em -zinho, uma consoante epentética que emerge para satisfazer exigências estruturais. Dada a palavra morfológica como base e um "ranking" de restrições de correspondência, marcaşão e alinhamento como instrumento de análise, chega-se à explicação consubstanciada na teoria e nos dados.

Palavras-chave: diminutivo, fidelidade, alinhamento, marcaşão.

Absctract: This study makes a review of the analysis and interpretations of the diminutive in Portuguese, recovering the vision of Soares Barbosa (1789), obliterated by most of the analysis of the last century. Taking this point of view as reference, the hypothesis that guides this analysis, which is based on the Optimality Theory, is that-inho is the morpheme; and $z$ in -zinho, an epenthetic consonant. Considering the morphological word as base of the derivative and a ranking of correspondence, markedness and alignment constraints as the instrument of analysis, the explanation comes out firmed on the theory and on the data. Key-words: diminutive, faithfulness alignment, markedness.

\section{INTRODUÇÃO}

O meio mais produtivo de produzir diminutivo em Português consiste em agregar -inho ou -zinho a uma base nominal. Devido à semelhança dessas formas, diferentes interpretações lhe foram atribuídas, através dos tempos, com argumentos a favor de um só morfema ou de dois, mas longe parece estarmos de uma visão consensual. Diante da pergunta renitente, -trata-se de uma só forma ou de duas? - este estudo desenvolve a ideia de que existe apenas um morfema, que é -inho, o qual se reveste de uma consoante epentética para satisfazer exigências estruturais, manifestando-se como -zinho. 
O texto divide-se em quatro partes. Na parte I, delineia-se o Estado da Arte, conclamando as interpretações que se fazem presentes em estudos do português, desde os gramáticos antigos a nossos dias, sem a pretensão de exaurir a documentação existente. Na parte 2, faz-se a análise na linha da teoria da otimidade, com uma breve reflexão sobre a variação. Na parte 3 e na parte 4, discute-se o diminutivo-plural com o que se chega às conclusões finais em (5). A análise desenvolve-se com dados do português brasileiro.

\section{O DIMINUTIVO E SUA INTERPRETAÇÃO ATRAVÉS DOS TEMPOS}

Na primeira gramática portuguesa (2007, p. 140; [1536, p. 61]), Fernão de Oliveira faz uma ligeira menção ao diminutivo e aumentativo, considerando-os palavras tiradas, isto é, derivadas. Exemplifica com a forma -inho, sem fazer menção a -zinho. "... é regra geral que os nomes (...) diminutivos acabem em inho ou inha como mocinho, mocinha; e os aumentativos em az e ão.

Na Grammatica Philosóphica da Língua Portugueza de Jerónimo Soares Barbosa, cuja primeira edição (1823) com prefácio de 1803 permite situá-la no século XVIII, como o título sugere, inspirada que foi na Escola de Port Royal, o diminutivo é mencionado como -inho e -zinho, mas como se as duas formas fossem uma só. O aparecimento de $\mathbf{z}$ é tido como um recurso de evitar o hiato:

Os diminutivos são os que mudando a terminação de seus primitivos, lhes diminuem mais ou menos a significação(...). Os que diminuem mais acabam ou em inho, inha, quando os primitivos terminam em vogal, consoante, como filhinho, filhinha, mulher, mulherinha, rapaz, rapazinho; ou em zinho, zinha, quando os primitivos terminam em diphthongo, como homemzinho, leãozinho, pãezinho, mãezinha. $\mathrm{O} z$ eufônico faz-se necessario na derivação d' estes diminutivos para evitar o hiato nascido do concurso de tres vogaes. (Barbosa, 1875,p.83)

Soares Barbosa faz também menção à coexistência de vocábulos como mulherinha, mulherzinha, em que $z$ aparece sem a referida necessidade. Mas mostra-se convicto de que é um segmento apenas eufônico.

É essa ideia surgida no século XVIII, mas não perquirida, que vamos retomar e elaborar neste artigo. Por ora continuemos o ligeiro recorte histórico.

Na Grammatica Descriptiva de Maximino Maciel (1916, p .166), com prefácio de 1894 , que a situa no século XIX, o diminutivo também é des- 
ignado como -inho, o qual pode apresentar-se com o afixo $z$ que considera obrigatório em nomes terminados por duas vogais, por sons nasais e em oxítonas, ex: labiozinho, cãozinho, sabiàzinha; mas facultativo nos demais casos.

Vale observar que houve um tempo em que o diminutivo e o aumentativo foram considerados flexão. Julio Ribeiro (1918, p.96), que também considera z uma consoante inserida, afirma: "A flexão nominal gradual consiste na desinência augmentativa ou diminutiva ao grau normal." Por grau ainda o entende Eduardo Carlos Pereira (1955, p.83): "Os substantivos variam em sua terminação, isto é, mudam de flexão, para indicarem os acidentes de gênero, número e grau", assim como Antenor Nascentes (1960), entre outros. Por muito tempo pairou a hesitação entre derivação e flexão, em virtude de semelhanças com a flexão que esse formativo apresenta. Tão somente no declinar do século vinte, a questão toma um só rumo, sob a égide de autoridades como Said Ali (1964), Cunha (1971), Rocha Lima (1972) e Cunha \& Cintra (1985). Então a alomorfia como o divisor das águas passa a ser tema de dissertações e artigos.

Um estudo diacrônico dos sufixos (Allen Jr, 1941), teve um papel importante nesta história ao justificar a epêntese de $\mathbf{z}$ por uma generalização: Assim como - al torna-se -zal, ão torna-se $-z \tilde{a} o e$-arrão $>$-zarrão, -inho $e$ ito tornam-se respectivamente -ziño e - zito.

Na linha de Allen Jr. Pottier (1968) declara que -z do português é análogo a $-\mathrm{c}([\mathrm{s}\rceil)$ do espanhol para o qual apresenta uma explicação em termos de tendência. A introdução desse segmento seria a tentativa de preservar o corpo silábico do primitivo. Perguntado por que mesa $>$ mesita, mas mujer > mujercita quando mujeril existe no espanhol, assim responde:

Mas aqui se trata de um diminutivo que apenas precisa a extensão quantitativa do lexema, sem atribuir-lhe um valor aspectual ou funcional como no caso de mujeril. O lexema permanece o mesmo; parece ser esta integridade o que se quer respeitar quando se introduz um -c- que permite conservar o tipo silábico. (Pottier, 1968, p.63).

No estudo minucioso de Maurer Junior (s/d), -zinho análogo a -cito do espanhol é tido como uma variante de -inho. Mas admite, abrindo o caminho para os que vão defender a independência de -zinho, no decorrer do século vinte, que, dado o uso intenso dessa consoante de ligação, -zinho tende 
a mostrar certa autonomia, opondo-se, como elemento da composição, a -inho, elemento da derivação. Tratar-se-ia de composição por justaposição com as seguintes características:

a) O vocábulo primitivo conserva sua fisionomia integral, inclusive as vogais tônicas abertas;

b) O feminino e o plural são marcados duas vezes, uma vez no primitivo e outra no diminutivo.

Câmara Junior (1975, p.217), chamando atenção para o fato de que processos de aglutinação e justaposição podem ocorrer tanto na composição quanto na derivação, considera a formação do diminutivo com -zinho um caso de derivação por justaposição. Tal processo cria uma locução em que o vocábulo fonológico correspondente tem a palavra primitiva e o sufixo, cada qual com sua flexão de gênero, como lobazinha, lobozinho exemplificam.

Leite (1974) defende que o diminutivo com zinho tem o status de composto, afirmando que há evidências fonológicas suficientes para sustentar essa hipótese, enquanto inexistem para-inho, embora alguns aspectos desse diminutivo acenem para essa direção. Argumenta com a flexão de número e de gênero que ocorrem em limite de palavra a que zinho é anexado. Quanto à insensibilidade do diminutivo à neutralização da pretônica apontada por seus predecessores, afirma que há outros derivativos que também levam uma marca especial que inibe essa neutralização. Na sua visão, -inho é um afixo e -zinho, uma entrada lexical.

Moreno (1977), que, em sua dissertação de mestrado, faz uma detalhada e preciosa revisão crítica dos estudos que ao seu precederam, considera que tanto inho como zinho são duas formas autônomas, e que as peculiaridades que lhes tem sido apontadas decorrem do cruzamento de planos em que o vocábulo está envolvido.

Parece-nos difícil, como diz Moreno (1977), abrigar a idéia da independência de -zinho com base na existência do substantivo zinho, como se o diminutivo fosse o indutor do substantivo, justamente o contrário do que ocorre com a formação dos advérbios em -mente, tomado como referência. $\mathrm{O}$ argumento aparentemente irrefutável em favor da autonomia de -zinho seria a flexão interna, sugerida pela presença de uma vogal interna interpretada como vogal temática, como em florezinhas $<$ flores, corezinhas $<$ cores. No entanto, é importante observar que há palavras na 
língua sem indicativo de pluralidade ou de gênero com essa vogal interna, como ervatário e lamascal.

Menuzzi (1993), por sua vez, apresenta -inho e zinho como dois alomorfes em distribuição complementar. Afirma que, embora -zinho preserve a estrutura morfológica da base e -inho ocorra na mesma posição derivacional dos demais sufixos, ambos são prosodicamente sufixos.

Lee (1995), na linha da Fonologia Lexical, ao considerar dois níveis lexicais na formação de palavras, alfa e beta, os quais corresponderiam à raiz e palavra respectivamente, considera que ambas as formas, -inho e -zinho, entram no nível alfa onde recebem acento, mas o processo de formação do diminutivo, seja com uma seja com outra forma, ocorre no nível beta, do que se infere que ambos são sufixos do nível da palavra.

Ferreira (2005), mais recentemente, admitindo dois alomorfes, inho para a raiz e zinho para a palavra, analisa o plural dos diminutivos sob a perspectiva da Teoria da Otimidade, apontando para o papel de restrições de correspondência do tipo output to output, quadro teórico que orienta a análise a ser apresentada na seção seguinte. ${ }^{1}$

A hipótese que dirige estas linhas, já mencionada, é que o sufixodiminutivo é tão somente -inho, que se manifesta com z- epentético para satisfazer exigências estruturais, ou seja, para atender a certos princípios ativos na interação da morfologia com a fonologia que são fundamentais para organização deste derivativo.

\section{ANÁLISE $^{2}$}

Os derivativos podem ter por base uma raiz, um radical, ou uma palavra morfológica ou fonológica. A base do diminutivo é a palavra morfológica, definida em termos da presença da vogal temática, doravante VT, ou de sua ausência, de acordo com a classificação exposta em (1). ${ }^{3}$

1. Agradeço ao revisor anônimo a indicação deste artigo.

2. Esta análise fonológica considera a interface morfologia e fonologia mas não se detém nos valores semânticos.

3. Para classificações mais detalhadas sobre vogal temática, ver Câmara Jr. (1970), Harris ( 1991 ) e Alcântara (2003). 
(1) Classificação morfológica dos nominais ${ }^{4}$
a) Temáticos
Tema em a,o,e
roz-a
bol-o
pared-e
b) Temáticos com ditongo nasal
Tema em o, e
mão/mãos
pão/pães
limão/limões
c) Atemáticos
Radical terminado em Soante ou /S/
d) Atemáticos
mar $\sim$ mares
mal $\sim$ males
Radical terminado em $\mathrm{V}, \mathrm{N}$ ou $\mathrm{L}$
café
homem
nariz $\sim$ narizes
papel $^{5}$

Os nominais de tema em /a/ e /o/, (1a), constituem as classes maiores. Nos primeiros, a vogal terminal, muitas vezes, funciona comoport-manteau, VT e gênero, menina, por exemplo. Os de tema em /e/ incluem não só palavras advindas das fontes originais da língua que se encaixam no esquema $\mathrm{Rad}+\mathrm{VT}$, vale, verde, por exemplo, mas também estrangeirismos licenciados pela vogal default como clube e lorde do Inglês club, lord. Os temáticos terminados com ditongo nasal, (1b), em sua maioria, mostram /e/ no plural e /o/ no singular. Vale notar que o português é uma língua de terminação predominantemente vocálica, isto é, as palavras temáticas constituem a maior parte de seu léxico.

Os nominais atemáticos subdividem-se em dois grupos: os terminados em soante ou /S/, (1c), que emergem com uma vogal na posição de VT somente no plural, mar mares, mal males, nariz narizes $e(1 \mathrm{~d})$, os correspondentes a um radical terminado em vogal, como abacaxi e caju ou em soantes L e N, papel, homem, os quais por si sós formam palavras lexicais.

É o nominal temático ou atemático que constitui a base de DIM. Essa base muitas vezes não vem diretamente à superfície, como é o caso dos nominais com terminação nasal que carregam uma nasal subespecificada, portanto não pronunciável ou que contêm /S/ pós-vocálico com sonoridade não definida no input.

4. Por nominais entendem-se substantivos e adjetivos.

5. Algumas palavras terminadas em L ficam na classes (1c) mas a maioria encaixa-se em (1d). 
Antes de iniciarmos a análise, apresentamos as propriedades de DIM em (2) e as restrições que conduzem esta análise em $(3)^{6}$ :

(2) Propriedades de DIM

Base Diminutivo
a) pat-o $\leftarrow$ patinho, *patoinho
(Evitação do hiato)
b) rọz-a $\leftarrow$ rozziña, *rozinha
(Fidelidade aos traços do input )
c) mar)
$\leftarrow$ mar.) zi.nho, *ma.ri.nho (Preservação da estrutura
d) lámpad-a $\leftarrow$ ('lãm.pa.da)(zi.nha) silábica da base)
e) flores $\quad \leftarrow$ florezinhas
(Preservação do acento marcado)
(Correspondência com o output)

(3) Restrições

ONSET: Toda sílaba deve ter onset

MAX-IO: Todo segmento do input deve ter correspondente no output. Apagamento é proibido.

MAX-Root: Todo segmento do radical deve ter correspondente no output.

DEP-IO: Todo segmento do output deve ter correspondente no input. Epêntese é proíbida.

IDENT-ATR: Segmentos correspondentes (input/output) são idênticos na dimensão ATR.

ALIGN-R (Base, $\sigma$ ): Alinhe a borda direta da base com a borda direita de uma sílaba.

IDENT-OO: A base de DIM deve estar em relação com o input e com o output

STRESS FAITHFULNESS: O acento subjacente guarda a mesma posição no output.

ANCHOR- PL: O morfema de plural $\{\mathrm{S}\}$ deve ancorar-se no vocoide mais à direita da palavra.

Todas as restrições citadas fazem parte da literatura de OT, embora Anchor tome uma visão particularizada. MaxRoot e MaxIO estão em relação de estringência, isto é, violar a primeira que é um subconjunto da segunda implica violar a segunda, mas não vice-versa, porque a segunda tem uma estringência maior(McCarthy 2002,p.40). A restrição Ident(ATR) dá conta de DIM ser isento da neutralização da pretônica. A restrição de alinhamento preserva o limite direito do input para evitar silabação descom-

6. As restrições são nomeadas em sua forma original. E no decorrer da análise usa-se o termo onset no lugar de ataque para não perder a relação com a restrição. Também, ao invés de estrutura subjacente e estrutura de superfície, usam-se os termos input e output, sugeridos pelas restrições Ident IO (input e output) e Ident OO (output e output). 
passada entre o output da base e do diminutivo. A preservação do acento marcado no input é controlada por Stress FAITHFULNESS. ${ }^{7}$ A restrição IDENT-OO diz respeito à relação de DIM com uma forma do output. A última, Anchor, é uma restrição de ordem morfológica e fonotática, pois o plural tem uma posição fixa na palavra determinada morfologicamente e uma demanda fonotática: exige o apoio de uma vogal ou glide, ou seja, um vocoide Ajusta-se plenamente a palavras temáticas ou atemáticas cujo radical termina em vocoide, como pato, patos patinhos ou café, cafés, cafezinhos, sarau, saraus, sarauzinhos, mas faz emergir uma vogal de apoio no plural de palavras acabadas em consoante, como em flor $>$ flores, mar $>$ mares, feliz $>$ felizes.

\subsection{EVITAÇ̃̃o DO HIATO}

GEN, que conhece os primitivos linguísticos, cria candidatos com acento e sílaba a serem julgados por COM, isto é, pelas restrições hierarquizadas (EVAL). Admitindo-se que os candidatos a serem analisados satisfaçam as restrições referentes à silabificação e ao acento, altas na hierarquia, essa parte não será discutida.

Dada a palavra morfológica como base e -inho como forma de DIM na estrutura subjacente, observemos os seguintes dados:
(4) a) pato + inho $>$ pa. ti nho. capa + inho $>$ ca.pi.nha.
b) café + inho $>$ ca.fe.zi.nho. cebola + inho $>$ ce.bo.li.nha. abacaxi + inho $>$ a.ba.ca.xi.zi nho. sofát inho $>$ so.fa.zi.nho.

A vogal temática é apagada em (4a), e DIM ajusta-se ao onset disponível. A vogal do radical é preservada em (4b), e entra /z/ para ser onset da vogal inicial de DIM. Em ambos os casos, o hiato é resolvido, satisfazendo a restrição do Onset.

Passemos da descrição à explicação formal no Tableau 1. O termo Radical (rad) será usado sem distinção de raiz, pois a base de DIM pode ser tanto um radical equivalente à raiz como flor $>$ florzinha como um radical derivado como floreira $>$ floreirinha.

7. Sobre Stress FAITHFULNESS, ver Hyde (2002) e Magalhães(2004) 


\section{Tableau 1: Nominal temático}

\begin{tabular}{|c|c|c|}
\hline /pato-íño/ & Onset & MaxIO \\
\hline a pa.to.í.ño. & $* !$ & \\
\hline b. pa.tí.ño. & & * \\
\hline
\end{tabular}

A forma ótima é (1b), que exibe DIM em uma sílaba com onset às expensas de Max. A exigência da restrição Onset é satisfeita, isto é, o hiato é evitado. A relação inversa das restrições em pauta privilegiaria o perdedor. Portanto, Onset domina Max na formação do diminutivo.

Os dados de (2b) no Tableau 2, com a vogal do radical preservada não põem à disposição uma consoante para onset, como ocorreu no tableau precedente. Então surge /z/ para satisfazer a exigência da restrição do onset. A restrição DepIO que proíbe epêntese é ativada.

Tableau 2: Nominal atemático

$$
/ \mathrm{kaf} \boldsymbol{\varepsilon} /_{\text {rad }=\text { base }}
$$

\begin{tabular}{|c|c|c|}
\hline /kafE-iño/ & Onset & DepIO \\
\hline a ka.fE.zi.ño. & & * \\
\hline b. ka.fe. i.ño. & *! & \\
\hline
\end{tabular}

Às expensas de DEP, (2a) é a forma ótima, pois satisfaz Onset. Da mesma forma que no Tableau 1, a relação inversa favoreceria o perdedor. Portanto, Onset domina Max e domina Dep. O morfema -inho que começa por vogal vem à superfície com onset, seja às custas de DEP-IO que proíbe a inserção de segmentos, Tableau (2), seja às custas de MaxIO que proíbe apagamento, Tableau (1). Em outros termos, a demanda da restrição Onset tem de ser atendida.

Todo nominal atemático, seja terminado em vogal que pertence ao radical caju $>$ cajuzinho, saci $>$ sacizinho, cajá $>$ cajazinho, seja terminado em 
consoante ou glide, pomar>pomarzinho, papel>papeizinhos, mingau mingauzinho, está comprometido com a relação Onset $>>$ DepIO.

Primeira tentativa de generalização: A consoante /z/ é introduzida para evitar hiato.

Reedita-se o que em tempos idos fora observado por Soares Barbosa, citado inicialmente. Entretanto existem outras motivações para a consoante epentética, como veremos a seguir. Mas antes detenhamo-nos em um ponto. Constatada a relação de dominância de Onset sobre MaxIO e sobre DepIO, uma pergunta desponta: E entre MaxIO e DepIO, qual é a relação? A resposta está no tableau seguinte, o qual mostra que apagamento de segmento do radical é mais custoso do que apagamento de segmento funcional, no caso, a vogal temática.

Tableau 3: Nominais temáticos e atemáticos

\begin{tabular}{|c|c|c|c|}
\hline /pato -iño/ & MaxRoot & DepIO & MaxIO \\
\hline a pa. ti...ño. & & & $*$ \\
\hline b.pa.to.zi.ño. & & $* !$ & \\
\hline \multicolumn{4}{|l|}{ /kafE-iño/ } \\
\hline c. ka.fi. ño & $* !$ & & $*$ \\
\hline$\sigma$ d. ka.fє.zi.ño & & $*$ & \\
\hline
\end{tabular}

Para nominais acabados em VT, como pato, patinho, (3a), é mais harmônico do que patozinho, (3b), embora essa opção não seja totalmente proibida (ver seção 3). Todavia, para nominais atemáticos, em que zinho é a única saída, em virtude de MaxRoot, alto na hierarquia, uma inversão entre DepIO e MaxIO traria o mesmo resultado. Em outros termos, enquanto para o segundo input a restrição mais alta é decisória, para o primeiro a decisão cabe às decisões mais baixas. Portanto DEPIO $>>$ MAXIO.

\subsection{FidelidAde}

Admitindo-se que a distinção entre vogais médias fechadas /e,o/ e médias abertas $/ \varepsilon, \mathrm{o} /$ se faça pelo traço ATR em termos de $[+\mathrm{ATR}]$ para 
as primeiras e [-ATR] para as segundas, depreende-se a característica mais citada de DIM, que é preservar o traço [ATR] da vogal média do input, diferentemente da maioria dos derivativos. No sistema fonológico do português, sílabas pretônicas derivadas de tônicas sofrem um processo de neutralização que, em dados do sul e sudoeste do País, manifesta-se via conversão da vogal média [-ATR $]$ em $[+A T R]$. Isto é, perde-se, na pretônica, a distinção entre média fechada e média aberta. Isso tem por

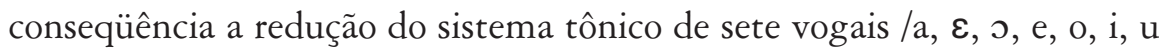
/ para cinco vogais átonas /a, e, i, u, o/ com reflexos na postônica que se reduz a três em posição final. $\mathrm{O}$ diminutivo $(5 \mathrm{~b})$, no entanto, fica fiel ao ATR da base (5a), ignorando essa redução:

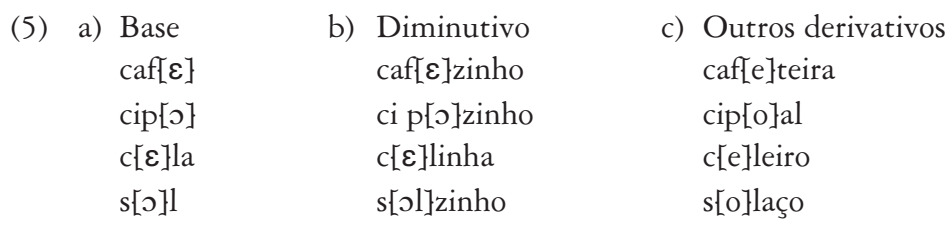

Tais exemplos sugerem que DIM é fiel aos traços fonológicos dos segmentos da base a que se anexa, o que formalmente o Tableau 4 explicita:

Tableau 4: Nominal atemático

$/ \mathrm{kaf} \varepsilon /_{\text {rad }}=$ base

\begin{tabular}{|c|c|c|c|}
\hline /kafE-iño/ & Ident-ATR & Onset & DepIO \\
\hline a ka.fE.zi.ño. & & & $*$ \\
\hline b ka.fE.i.ño & & $* !$ & \\
\hline c. ka.fe.zi.ño & $* !$ & & $*$ \\
\hline
\end{tabular}

O ponto importante aqui é a entrada da restrição Ident(ATR) prevista no ranking e definida anteriormente. $\mathrm{O}$ candidato (4c) altera o traço ATR da vogal do input e é rejeitado, enquanto o candidato ótimo, (4a), o preserva. O candidato (4b) é descartado, como seria qualquer candidato que apresentasse DIM sem onset. Portanto, a fidelidade nos termos de 
Ident-ATR e a presença de onset controlada pela restrição cognata, nãodominadas, dominam DEP-IO e MAX-IO, o que explica o apagamento de VT no Tableau 1 e a intromissão de /z/ no Tableau 4. Vemos, pois, que a consoante $/ z$ / é introduzida também para preservar o traço ATR de nominais atemáticos; os demais o preservam sem recurso especial, como, por exemplo, bola $>$ boliña.

Segunda tentativa de generalização: $O$ diminutivo, que evita hiato, é preservador dos traços fonológicos dos segmentos da base a que se anexa.

\subsection{Interface Morfologia e Fonologia}

O diminutivo oferece elementos para ser interpretado como composto ou como um derivativo por justaposição, o que pode ser apreciado quando da revisão histórica se tratou, porque processos dessa ordem deixam intactas as posições da palavra com que se relacionam. Isso se explica pelo alinhamento de bordas.

(6) Alinhamento da borda direita da base com a borda direita da silaba sol.]

sol.]zi.nho *so.li.nho

po.mar.]

po.mar.].zi.nho. *po.ma.ri.nho

mar.]

mar.]zi.nho. *ma.ri.nho (a não ser com outro sentido)

pe.rau.]

pe.rau.]zi.nho. * * pe.rau.i.nho

Tableau 5: interface

$/ \mathrm{sol} /{ }^{8} \mathrm{rad}=$ base

\begin{tabular}{|l|l|l|l|l|}
\hline / sol -iño/ & IdentATR & AlignR & Onset & DepIO \\
\hline a. soł.zí.ño & & & & $*$ \\
\hline b. soł. í.ño & & & $* !$ & \\
\hline c. so.lí. $\mid$ ño & & $* !$ & & \\
\hline d soł.zi.ño & $* !$ & & & $*$ \\
\hline
\end{tabular}

8. Vale lembrar que no lugar da lateral dorsal poderia figurara o glide posterior, uma variante de uso comum no português brasileiro. 
A restrição de alinhamento, ao exibir coincidência da borda direita da base com a borda direita de uma sílaba faz com que a estrutura silábica da base seja mantida no derivativo, como mostram os exemplos em (6) e a análise no Tableau 5 explica, justificando a entrada de /z/. Para facilitar a leitura, valemo-nos do sinal ( | ) como indicativo de bordas desalinhadas. A restrição AlignR desaloja (5c), porque está desalinhado, isto é, a borda direita da base não coincide com a borda direita de uma sílaba. O vencedor é (5a). A ordem inversa entre AlignR e DepIO favoreceria o perdedor. Por fim (5d) é descartado, como seria qualquer candidato que não preservasse o traço ATR da base. Note-se que as restrições que dão conta das propriedades do diminutivo exemplificadas em (2) exibem a seguinte relação: Onset, AlignR, IdentATR $>>$ DepIO $>>$ MaxIO, todas sob o domínio de restrições mais altas, entre as quais MaxRoot. ${ }^{98}$

As variantes que constituem exceções à entrada de /z/, isto é, que ignoram a restrição AlignR são raras, entre elas, colberinha e florinha. A primeira sobrepuja sua contraparte na freqüência de uso; a segunda, ao contrário, é sobrepujada por florzinha. Há também exceções que adquirem um novo sentido como, por exemplo, mulherinha, bisbilhoteira ou outro sentido pejorativo, e painho ou mainha, expressões de carinho ou de tratamento para autoridades do Candomblé.

Note-se que em nominais atemáticos, cuja borda direita é perdida em virtude do apagamento da vogal, a restrição de alinhamento é atendida no vazio ( in vacuun). Por exemplo, em pato, CVCV, Tableau1, a vogal inicial de DIM ajusta-se à consoante final da base e restaura a sequência CV cuja vogal fora apagada, mantendo a sua posição de onset.

Do exposto infere-se, abrindo o caminho para a generalização final, que DIM exige onset e preserva os traços fonológicos e a posição estrutural dos segmentos da base a que se anexa, revelando perfeita simetria entre a métrica da base e a métrica de DIM.

Deixando para o final a discussão sobre o plural do diminutivo em que aponta uma particularidade, vamos fazer uma breve pausa para uma reflexão sobre a variação que não será objeto da análise formal em pauta.

9. Fazem parte do grupo analisado no Tableau 5 palavras de radical terminado em /S/ que sofrem fusão em virtude de OCP: rapaS + iño $>$ ra.paz ${ }_{1} \cdot z_{2}$ i.ño $>$ ra.pa.z $z_{1,2}$ i.ño. 


\section{INTERMEZZO: O DIMINUTIVO E A VARIAÇÃO}

Todos os casos de introdução de consoante / $\mathrm{z} /$ constituem uma demanda estrutural, seja resolver um problema organizacional de DIM como ter onset seja preservar traços fonológicos ou alinhar fonologia e morfologia. As exceções são poucas ou de uso menos freqüente e podem ser enumeradas ou tomam um sentido particular. A variação circunda-se aos nominais temáticos em que se impõe a prevalência da forma original -inho. Todavia ao lado da analogia que abre as portas para /z/ em nominais temáticos, há casos em que a epêntese é motivada. É o que vamos expor.

\subsection{DIM E O GÊNERO GRAMATICAL}

DIM, como todo morfema derivativo, em posição final, é o portador do morfema de gênero da palavra, independentemente do sentido que possa ter. Diante disso, se DIM, ao invés de apagar VT, como o faz comumente em nominais temáticos, deixa-a intacta, haverá redundância de informação, o que, em nome da simplicidade, tende a ser evitado. Não há erros, mas redundância de informação.

(7) borboleta > borboletinha, borboletązinha (!)

pato $>$ patinho, patozinho $(!)$

garota $>$ garotinha, garotazinha $(!)$

O que se faz notar é que, nesse caso, a redundância tende a ser evitada.

Todavia, há casos de disparidade entre VT e gênero da forma base e do diminutivo. Nesses a consoante /z/ é introduzida para preservar a vogal da base, manifestado-se, dessa forma, ambas as vogais, a da base internamente e a de DIM que porta o gênero na posição que lhe é destinada. Isso acontece com nominais de gênero masculino com VT /a/, com nominais do gênero feminino com VT /o/ e com nominais pertencentes à categoria "comum de dois".

(8) o aroma o aromazinho a contralto a contraltozinha o/a pianista o pianistazzinho, a pianistazinha 
São os nominais que pertencem à classe da vogal temática /e/, destituída de qualquer relação com gênero, que abrem as portas para variação analógica:

(9) verde: verdinho verdezinho parede: paredinha $\sim$ paredezinha corrente: corretinha $\sim$ correntezinha

Por conseguinte, a variação em nominais temáticos está comprometida com o gênero gramatical.

\subsection{DIM E OCP}

Seqüência de segmentos idênticos, proibida pela condição de boaformação referida por OCP, princípio do contorno obrigatório, é solucionada pela introdução de /z/, (10a), enquanto uma seqüência de segmentos semelhantes, mas não idênticos, prefere a forma canônica, com a opção de optar pela despalatalização da consoante da base (10b).
(10) a) vinho: vinhozinho, *vinhinho
b) velho $>$ velinho
pinho: pinhozinho, *pinhinho
relho $>$ relinho
linho: linhozinho, *linhinho
palha $>$ palinha

\subsection{DIM EM NOMINAIS TERMINADOS EM HIATO}

Palavras acabadas em hiato invariável constituem um dilema para DIM, pois a parte final da base prosódica não oferece, como nos demais nominais temáticos, uma consoante para onset de DIM (ver Tableau1). De um lado, via apagamento de VT, ka.no.a $>$ ka.no.í.ña, o hiato da base é desfeito e o de DIM permanece. De outro, via epêntese, ka.no.a $>$ ka.no.a.zi.ña, o hiato da base é preservado para resolver o de DIM. As ocorrências mais freqüentes indicam que DIM tende a preservar o hiato do input e resolver o que lhe diz respeito, optando pela epêntese, mas a variação não fica de todo excluída, como (11) exemplifica, embora o mais das vezes tome um sentido particular, como coroinha, auxiliar de cerimônia religiosa na Igreja Católica.

(11) atoa $>$ atoazinha $\sim$ atoinha canoa $>$ canoazinha $\sim$ canoinha garoa $>\sim$ garoazinha $\sim$ garoinha 


\subsection{DIM E O ACENTO MARCADO}

Lancemos um breve olhar sobre o acento. O português tem por base rítmica um pé binário de cabeça à esquerda, por troqueu designado, que se organiza a partir da borda direita da palavra. É de notar que a sílaba final é acentuada se for pesada. $\mathrm{O}$ acento secundário desenvolve pés binários sem considerar o peso silábico. ${ }^{10}$

Em se tratando de diminutivos, a base que contém minimamente duas sílabas exibe pé binário de cabeça à esquerda. $\mathrm{O}$ acento secundário, quando herdado do principal, pode mudar de lugar para evitar choque acentual. A exceção está no grupo das proparoxítonas, que foge ao padrão geral, mostrando um dátilo, o qual tende a ser preservado por DIM.

(12) (lám.pa.da), (làm.pa.da.)(zí.nha), *(làm.pa)(dínha).

(cá.te.dra), (cà.te.dra).(zí.nha.), *(cà.te.)(.drínha.)

(cór.re.go),(càr.re.go).zí.nho.), *(còr.re.)(guí.nho)

Entre as proparoxítonas, há as que perdem uma sílaba, ajustando-se ao troqueu como abóbora $>$ abobra ou permutam variavelmente dátilo e troqueu como péssego, pèsseguínho pèssegozínho. A maioria, todavia, tende a preservar o pé datílico, herdado da palavra base, como catedrazinha, *càtredrínha, córrego > còrregozínho, *correguínho, mantendo-se fiel ao acento marcado no input, via acento secundário. Embora não tenhamos a intenção de discutir formalmente a variação, terminemos esta seção com a análise de um dátilo, ativando a restrição StressFaithfulness, definida em (3), que cuida da preservação de acentos marcados.

Tableau 6: proparoxítonas

/laNpad/ ${ }_{\text {rad }} /$ laNpada/ base

\begin{tabular}{|l|l|l|l|}
\hline I' laNpada - iña/ & StressFaith & MaxIO & DepIO \\
\hline a a ( 'ãm.pa.da.) (zí.ña) & & & $*$ \\
\hline b. lãm. (pà da.) (zí.ña) & $* !$ & & \\
\hline c. ( ' lãm. pa.) (dí. ña) & & $* !$ & \\
\hline
\end{tabular}

10. Sobre acento em português via OT, ver Magalhães (2004) e Lee (2007). 
Todos os candidatos satisfazem Onset e as demais restrições relevantes não ativadas. Sob o domínio de Stress-Faith, inverte-se a relação de dominância entre Dep e Max que passa a ser Max $>>$ Dep. A forma (6b) é descartada, porque viola a restrição mais alta. A decisão entre (6a) e (6c) fica ao encargo das restrições mais baixas: DEP aponta o deslize e MaxIO condena (6b). O vencedor é (6a). Mais uma vez, a presença de /z/ tem motivação estrutural.

Em suma, a variação analógica na área dos nominais temáticos existe, mas há casos que apontam para o controle de certos fatores, como redundância de gênero, hiato duplicado, acento marcado e OCP que motivam ou restringem a presença da consoante epentética. Feitas essas considerações, voltemos às propriedades de DIM para completar a análise.

\section{O PLURAL EM Diminutivos}

Partimos do pressuposto de que o morfema plural, $\{\mathrm{S}\}$, é somente [s] ou $[z]$, o qual se anexa a um vocoide em final de palavra, bola $>$ bolas, rei $>$ reis, mau $>$ maus, café $>$ cafés, pertença esse vocoide ao radical ou à vogal temática, mas não se anexa diretamente a uma consoante, valendo-se no caso da epêntese de uma vogal, mar $>$ mares, mas não *mars. $\mathrm{O}$ argumento é a coda complexa, a qual é bem formada, quando satisfaz a condição de C1 na coda ser soante, incluindo o glide, e C2, uma consoante continua, coronal, como em perspectiva, perspicaz, solstício, fausto, aneis, maus, mas é excluída se /S/ for morfema de plural: *mars, *flors, *mels. Alinham-se exemplos em (13), onde em (a) e em (c) a coda bem formada emerge, mas não em (b), pois o plural exige o apoio de um vocoide.

(13) Coda complexa

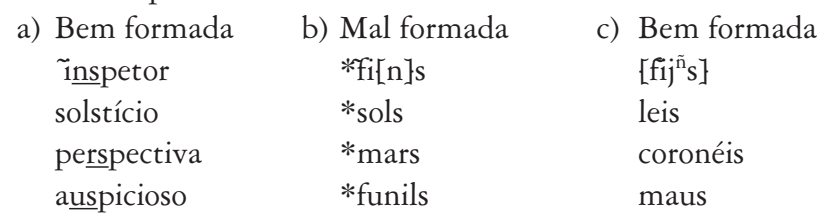

Deixando-se de lado os detalhes da pluralização para não nos afastar do foco deste estudo, retomemos o plural de diminutivos de palavras acabadas em soante. 


\subsection{DIM EM NOMINAIS ATEMÁTICOS COM VOGAL DIANTE DO PLURAL}

No plural de nominais atemáticos terminados em consoante, DIM relaciona-se com a base de uma forma do output, produzida por afixação do plural, como (14) sinaliza, sem deixar de ser fiel ao input.

$\begin{array}{ll}\text { (14) mar, mares } & >\text { marezinhos } \\ \text { pomar, pomares } & >\text { pomarezinhos } \\ \text { lar, } & \text { lares }>\text { larezinhos } \\ \text { flor, flores } & >\text { florezinhas } \\ \text { mal, } & \text { males }>\text { malezinhos }\end{array}$

Uma das vias de explicação de fatos como esse, na perspectiva da OT, é a proposta de Benua (1997), denominada Transderivacional Correspondence (TCT), entendida nos termos seguintes:

Considerando-se que a relação de correspondência que se estabelece entre input e output (IO) também possa estabelecer-se entre output e output (OO), para dar conta de fonologias motivadas morfologicamente, o modelo proposto vale-se da relação dupla, sintetizada em (15), em que a seta vertical indica a relação entre input / output e a seta horizontal, a relação output / output. Essa relação tem um papel relevante na seleção de bases paradigmáticas. Diferentemente do input que não está sujeito a nenhuma restrição, a base de um paradigma deve ser sempre uma forma lícita e canônica. Nossa análise, no entanto, firma-se em um ponto diferente com respeito à proposta original.Enquanto em Benua, cada output de B é comparado com o seu output correspondente em A, em nossa analise, cada output de B é comparado com o output vencedor de A. Doravante os tableaux que lidam com Ident-OO exemplificam essa versão. Note-se que os efeitos de ciclicidade, morfologicamente motivada, devem-se à recursividade via restrição de correspondência output-to-output, o que, de certa forma, remete à derivação seriada.

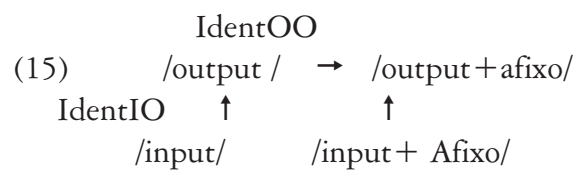


Tableau 7: Plural de nominais acabados em /r/

$$
/ \mathrm{mar}{ }_{\mathrm{rad}=\text { base }}
$$

Recursividade-A

\begin{tabular}{|l|l|l|l|l|l|}
\hline$/ \mathrm{mar} / \mathrm{PL}$ & IdentOO & Anchor & AlignR & DepIO & Max-IO \\
\hline a.ma.res & & & $*$ & $*$ & \\
\hline b. mars & & $* !$ & & & \\
\hline
\end{tabular}

Recursividade-B

\begin{tabular}{|l|l|l|l|l|l|}
\hline$/$ mar-iño/PL & IdentOO & Anchor & AlignR & DepIO & Max-IO \\
\hline a. mar.zí.ños. & $* !$ & & & $*$ & \\
\hline b.ma.re. zí. ños & & & $*$ & $* *$ & \\
\hline
\end{tabular}

$\mathrm{Na}$ recursividade $\mathrm{A}$, a restrição Ident-OO opera in vacuum e na recursividade $\mathrm{B}$ avalia aos pares os candidatos de (7B), relacionando cada um deles com a forma ótima de (7A), isto é, mares, ao mesmo tempo que o candidato é avaliado por MaxIO em relação à fidelidade ao input. Com a exceção de Ident-OO, todas as restrições avaliam item por item, isoladamente, seguindo o procedimento geral.

De acordo com a Condição de Coda, especificamente Coda Complexa, que licencia grupos de soante $+/ \mathrm{S} /$, os dois candidatos de $(7 \mathrm{~A})$ apresentam rimas bem formadas, como perspectiva e solstício exemplificariam, razão por que a restrição referente à coda complexa não foi ativada. Todavia essas rimas não são aceitas em final de palavra com S-plural, porque esse morfema exige o apoio de um vocoide, isto é, a restrição Anchor tem de ser satisfeita. Portanto, na recursividade A, a forma ótima é (7a) que mostra o plural apoiado em uma vogal epentética, às expensas de DepIO. É, pois, com mares, que a base do diminutivo-plural tem de estar relacionada. $\mathrm{Na}$ recursividade B, o S-plural interno (7c) é rejeitado por Anchor. O vencedor é (7b), o qual é fiel a Ident-OO, sem deixar de ser fiel ao input, razão por que MaxIO foi ativado, embora não haja candidatos que a violem. ${ }^{11}$

11. Observe-se que a restrição de Alinhamento que preserva o limite da base, justificando um dos casos de entrada de z, mar > marzinho, por exemplo, é violada no plural, porque está dominada por Anchor. 


\subsection{NOMINAIS ATEMÁTICOS TERMINADOS EM LATERAL}

Um dos casos interessantes do complexo morfofonológico é o da pluralização de palavras terminadas em lateral, das quais algumas se valem de vogal epentética, seguindo o padrão que acaba de ser descrito, mal $>$ males, mas a maioria não exibe VT em nenhum domínio seja fonológico seja morfológico, diferentemente do que ocorre com o espanhol el papel los papeles. Em português, a lateral final caracteriza nominais atemáticos, realizando-se como lateral dorsal ou glide [+ posterior], (16a). Todavia diante do morfema plural /S/ toma a forma de um glide coronal ou fundem-se as vogais quando idênticas(16b,c):

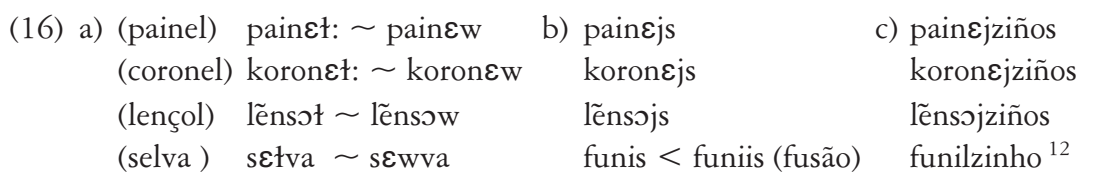

De acordo com Walsh(1995), a líquida lateral contém os traços coronal e dorsal, do que se infere que os glides [ \pm post $]$, (16), são provenientes dessas propriedades. A sua realização como glide $[+$ post $]$ em posição final (16a) é freqüente no português brasileiro, embora no Sul do País a lateral coronal, nesta posição, seja ainda uma presença a notar. A sua realização como glide [-post], (16b), morfologicamente consagrada, encontra-se também fora do contexto da pluralização, como variedade de um sistema fonológico, registrado por Harris (1983, p.47) em cibaeño, um dialeto do espanhol:

(17) revolver $=$ revoivei

$$
\begin{aligned}
& \text { carta }=\text { caita } \\
& \text { papel = papei } \\
& \text { algo }=\text { aigo }
\end{aligned}
$$

Feitas essas considerações que dão sustento à suposição de que os glides, como variantes da lateral, são manifestações de propriedades da lateral, voltemos aos dados de (16). Uma pergunta se impõe: Por que o morfema de plural que exige a presença de um vocoide, de acordo com Anchor, não

12. Vem se fazendo notar, na fala popular, o diminutivo com a perda da lateral final, possivelmente facilitada pelo processo de enfraquecimento por que vem passando a lateral através dos tempos: $1>$ ł > w. Daí: facinho por facilzinho faci[w]zinho, com perda da lateral e fusão dos dois /i/s, o do radical e o de -inho. 
se satisfaz com o glide [w] , papel > pape $(w)$ que se manifesta no singular, no português brasileiro? Tudo indica que a opção pelo glide [-post] é uma questão de harmonia, pois em jS, o glide comunga o traço coronal de /S/, tornando-se, neste sentido, a opção consagrada. Note-se que isso se mantém tanto na palavra base quanto no diminutivo: papéis, papeizinhos. ${ }^{13}$

Processos de harmonia vêm sendo amplamente descritos na literatura, sobretudo quando alvo e o gatilho são fonológicos. Todavia existem harmonias com alvo ou gatilho morfológico, seja por serem conduzidas por traços da raiz seja por serem delimitadas a afixos, segundo Archangeli and Pulleyblanck (2007). No caso em estudo, a harmonia é motivada pelo morfema de plural $\{\mathrm{S}\}$, o gatilho, e é delimitada à lateral final do radical, o alvo. ${ }^{14}$ A intervenção de Anchor que exige o deslocamento de /S/ para o fim da palavra por determinação morfológica não altera o resultado esperado. Em termos de regras, teríamos de contar com (18); em termos OT, com uma restrição da família Agree, definida em (19).

(18) Regra

Variantes condicionadas da lateral pós-vocálica

a. $/ \mathrm{l} / \rightarrow[\mathrm{j}] / \ldots$ PL]

b. Nos demais casos de coda, realiza-se como [ł] ou [w ]

(19) Restrição Agree

A seqüência glide e $\{\mathrm{S}\}$, onde o morfema-plural $\{\mathrm{S}\}$ é coronal, deve concordar em coronalidade.

Admitindo-se que toda restrição de harmonia esteja em conflito com uma restrição de fidelidade, vemos no Tableau 8, onde /1/ pós -vocálico está por [ł] ou [w], que a relação de dominância se estabelece em termos de Agree $>>\operatorname{Ident}(\mathrm{F})$. A última é uma versão mais ampla de Ident(ATR). Note-se que, para a descrição do diminutivo de tais nominais, novamente uma relação transderivacional se faz presente.

13. Sobre a variação da lateral na coda, ver Tasca (1999) e Espiga (2001).

14. Palavras cuja substituição da lateral pós-vocálica por glide posterior está consagrada na fala e na escrita de tal modo que a memória desta relação foi perdida, embora haja vestígios, como, por exemplo, chapéu, chapelaria, estão fora da concordância de coronalidade. Há também as que constituem exceções como gol [gow] com o plural [gows]. Por outra, em algumas variedades do português brasileiro, a harmonia referida estende-se a palavras com terminação nasal, como em tons, [tõ ws] tỗjs], por exemplo. 
(20) IdentOO

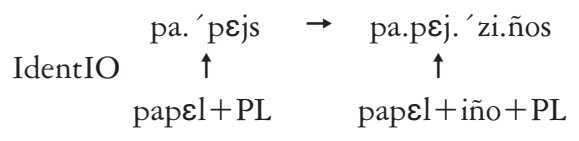

Tableau 8: Plural de nominais acabados em lateral

Recursividade A

\begin{tabular}{|l|l|l|l|l|l|l|}
\hline$/$ papel/ & IdentOO & Anchor & Agree & AlignR & IdentF & DepIO \\
\hline a.pa.pejs. & & & & & $*$ & \\
\hline b.pa.pews. & & & $* !$ & & & \\
\hline c.pa.pe.les. & & & & $* !$ & & \\
\hline d.pa.pels. & & $* !$ & & & & \\
\hline
\end{tabular}

Recursividade B

\begin{tabular}{|c|c|c|c|c|c|c|}
\hline /papcis- iño/ ${ }_{P L}$ & IdentOO & Anchor & Agree & AlignR & IdentF & DepIO \\
\hline$\varpi$ a.pa.'pej.zi.ños & & & & & * & * \\
\hline b.pa.'pew.zi.ños. & $* !$ & & $*$ & & & $*$ \\
\hline c.pa. 'pejs.zi.ño. & & $* !$ & & & $*$ & $*$ \\
\hline d. pa.pel.zi.ños & $* !$ & & & & & $*$ \\
\hline e. pa.pe.li.ños. & & & & $* !$ & & \\
\hline
\end{tabular}

O candidato ótimo na recursividade A e na recursividade B é (8a), que viola IdentF para satisfazer Agree. Os demais são rejeitados, em A, $(8 \mathrm{~d})$, porque não atende à demanda de um vocoide para apoio de PL, em (8c) por violar AlignR e em (8b) por ser desarmônico. Na recursividade $\mathrm{B}$, a restrição que compara os candidatos aos pares, Ident-OO desaloja as formas $(8 \mathrm{~b}, \mathrm{~d})$, porque as suas bases não se relacionam com a forma ótima de primeira recursividade. Anchor desaloja (8c) com plural no interior da palavra e AlingR(8d) por estar desalinhado. ${ }^{15}$

15. A palavra papelinho, lembrada por um dos revisores como uma forma comum no português europeu, encontra-se entre os perdedores no Tableau 8. Isso não quer dizer que seja mal formada, mas quer dizer que papelzinho é preferida a sua contraparte papelinho no português brasileiro, foco deste estudo, realizado sob o prisma da teoria da otimidade. 


\subsection{Nominais Temáticos Com Ditongo NASAL}

Da mesma forma que nos dois casos precedentes, uma relação output to output se estabelece com as terminações de ditongo nasal, como mostra Benua (1997) que tomou o português como um de seus exemplos. Respeitadas as diferenças de análise já mencionadas, o tableau 9 põe em evidência a relação output-to-output.

Segundo Câmara Jr. (1975, p. 83), ainda no português arcaico, palavras terminadas em /e/ precedido de segmento nasal, cedo perderam o /e/ final do tema: ratione $>$ razom, pane $>$ pan. A partir daí, a língua organizou-se de tal modo que essas palavras passaram a exibir /e/ como tema somente no plural, confluindo, no singular, para ão, razão, pão. Isto é, enquanto as de radical aN com vogal temática /o/ mantém essa vogal no plural, cidadão(s) irmão(s) mão(s), as de radical /oN / têm vogal temática alternante, /o/ no singular e /e/ no plural. Nessa classe também entram algumas palavras de terminação /aN/. ${ }^{16}$ Em suma, as formas de singular tem a vogal temática /o/, enquanto as de plural mostram as variantes /o/ e /e/.

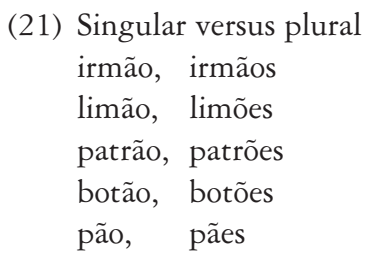

Partimos do pressuposto de que tais palavras têm, no input, um elemento nasal, subespecificado, simbolizado por N. Esse elemento subespecificado que não pode ser apagado, (MaxN controla), deve incorporar-se em receptores de nasalidade que são, neste sistema, vogais e glides.

A nasalização em si mesma não será discutida, mas, sim, a boa formação do diminutivo. A partir do input, duas vogais em sequência formam um ditongo nasal. À vogal /o/ levantada para [u] corresponde um glide $[+$ post [ e à vogal /e/ levantada para [i] corresponde um glide [-post].

16. Câmara (1970) já chamara atenção sobre o uso freqüente das variantes ãos- ões, por exemplo, anão $>$ anãos $\sim$ anões. 
Afora os ditongos nasais com a mesma vogal temática no singular e no plural, os demais estabelecem uma relação output to output no estilo delineado em páginas precedente. O Tableau 9 expõe a análise de pão com VT-o e pães com VT-e, de acordo com o exposto.

Tableau 9: Plural de Nominal com ditongo nasal alternante Recursividade-A

\begin{tabular}{|l|l|l|l|l|l|l|}
\hline$/$ paN-o $/$ PL & IdentOO & Anchor & AlignR & Agree & IdentF & MaxIO \\
\hline a. pãjs. & & & & & $*$ & \\
\hline b. pã w̃s. & & & & $* !$ & & \\
\hline c. pãns. & & $* !$ & & & & \\
\hline d. pã.nes & & & $* !$ & & $*$ & \\
\hline
\end{tabular}

Recursividade-B

\begin{tabular}{|l|c|l|l|l|l|l|}
\hline /paN-e-iño/PL & IdentOO & Anchor & AlignR & Agree & IdentF & MaxIO \\
\hline a. pã̃ .zi.ños & $* !$ & & & $*$ & $*$ & \\
\hline b.pãj.zi.ños & & - & & & $*$ & \\
\hline c. pã.ne.zi ños & $* !$ & & $*$ & & $*$ & \\
\hline
\end{tabular}

O vencedor na recursividade A é (9a), que oferece a base para a recursividade $\mathrm{B}$ que a reanalisa em termos de $\mathrm{paN}+\mathrm{e}+\mathrm{S}$. Em A, Anchor desloja (9c), porque o morfema plural exige o apóio de um vocoide. A restrição AlignR que proíbe atravessar o limite direito da base, na silabificação de DIM, bastante ativa nesta análise, aqui se faz presente para bloquear os candidatos (9d) na recursividade A e (9c) na recursividade B, os quais transpuseram o limite direito da base, perdendo a coincidência exigida. Por sua vez, em B, a restrição IdentOO que examina cada candidato em relação ao vencedor da recursividade A, rejeita (9a) e ( 9c), que com ela não mostram vínculos. O vencedor na segunda recursividade é (9b) que satisfaz as restrições mais altas às expensas de Ident-F.

E assim chegamos ao fim desta análise com a seguinte generalização:

O Diminutivo, cuja forma canônica é -inho, exige onset e preserva os elementos da base (input) e do output que são relevantes para sua estruturação como palavra fonológica. 


\section{CONCLUSÃo}

A análise desenvolvida na linha da Teoria da Otimidade pode justificar todas as principais propriedades do diminutivo que são as seguintes: i) evitação de hiato; ii) fidelidade aos traços do input; iii) fidelidade à estrutura silábica da base e iv) recorrència a uma forma de output no plural de certos diminutivos de base atemática. As duas primeiras dizem da relação direta desse formativo com o input e as duas últimas são de interface.

Cabe-nos ressaltar, mais uma vez, que a interpretação do segmento z como epêntese é uma idéia antiga que remota ao século XVIII e que se estende a outros outros derivativos, como al zal, eiro zeiro, ão zão, arrão zarrão. Sob a égide da hipótese o morfema é canonicamente -inho, a contribuição deste estudo reside na elucidação dos condicionamentos para a epêntese, e na formalização da proposta com fundamentação teórica.

Deixando-se de lado a variação que não foi formalmente discutida, a gramática básica de DIM com respeito ao português brasileiro pode ser sumariada no seguinte diagrama:

(22) Anchor, MaxRoot, Ident-OO, Agree $>>$ Onset, Ident-ATR, AlignR

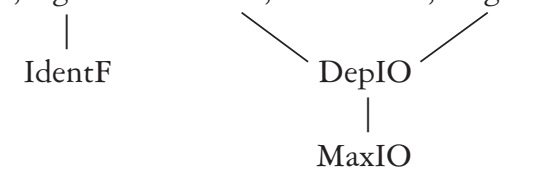

Por fim, repete-se o refrão que acompanhou todo o desenvolvimento da análise: $O$ diminutivo mais freqüente da língua é tão somente -inho que se reveste de $z$ epentético para satisfazer as demandas de sua organização estrutural.

Recebido em agosto de 2009 Aprovado em março de 2010 E-mail: bisol@pucrs.br 


\section{REFERÊNCIAS BiBLIOGRÁFICAS}

Alcantara, Cíntia da Costa. As Classes Formais do Português e sua Constituição. Um estudo à luz da teoria da Morfologia Distribuída. Tese de Doutorado, Porto Alegre, PUCRS, 2003.

Allen Jr., Joseph H.D. Portuguese. Word-fomation with Sufixes. Baltimore, Linguistic Society of América. Separata de Language, 17 (2): 3-143, 1941.

Barbosa,Jerônymo Soares Gramática Philosophica da Língua Portugueza. $6^{\text {a }}$ edição.Lisboa:Typographia da Academia geral de Ciências de Lisboa, (1875).[1787].

Barreto, Mário. Novos Estudos da Língua Portuguesa. Rio de Janeiro: Francisco Alves, 1911.

Bechara, Evanildo Moderna Gramática Portuguesa. São Paulo: Lucerna, 2006.

Benua, Laura . Positional Faithfulness. Doctoral Dissertation. Amherst, University Of Massachusett: ROA-231,1997

Camara Jr., J. Mattoso. Estrutura da Língua Portuguesa. 13 aed. Petrópolis: Vozes, 1970.

História e Estrutura da Lingua Portuguesa. Rio de Janeiro: Padrão, 1975.

Cunha, Celso. Gramática do Português Contemporâneo. $2^{\mathrm{a}}$ ed.BeloHorizonte: Bernardo Álvares, 1971.

\& L. Cintra. Nova Gramática do Português Contemporâneo. Rio de Janeiro: Editora Nova Fronteira, 1985.

Espiga, Jorge. O Português dos Campos Neutrais. Um Estudo Sociolinguístico da Lateral Pós-vocálica. Tese de Doutorado, Porto Alegre, PUCRS, 2001.

Ferreira, Marcelo (2005). Diminutives in Brazilian Portuguese and OutputOutput Correspondence. In Theoretical and Experimental Approaches to Romance Linguistics. Gess, Randall S. and Edward J., Rubin (eds). NewYok:John Benjamin Publishing Company, 2005,109-123.

Harris, J,W. The Formal Classes of Spanish Substantives. Morphology Yearbook 1:1991,65-88.

Hyde, Brett. A Restrictive Theory of Metrical Stress. Phonology 19.3: 2002, 313-359.

Kager, R, Feet and Metrical Stress. In The Cambridge Handbook of Phonology, Paul de Lacy(ed).Cambridge:Cambridge University Press,2007,195227. 
LeE, Seung-Hwa (1995).Morfologia e Fonologia Lexical do Português. Tese de Doutorado. Universidade Estadual de Campinas, 2007:195-227.

O Acento Primário em Português: uma análise unificada na teoria da otimidade In $O$ acento em português. Abordagens Fonológicas. Araújo,Gabriel Antunes et alii (org.). São Paulo: Parábola, 2007, $121-43$.

LeITe, Yonne de Freitas. Portuguese Stress and Related Rules. Tese de Doutorado. Universidade de Texas, 1974.

Maciel, Maximino Gramática Descriptiva 9ªed. Rio de Janeiro: Francisco Alves, 1925,[1916].

McCarthy, John J\& Allan PrInce. Prosodic Morphology I. Constraint Interaction and Satisfaction. Report no. RuCCS-TR-3. New Brunswick, HJ: Rutgers University Center for Cognitive Science. Available in ROA, 1993.

Magalhães, José, S. de. O Plano Multidimensional do Acento na Teoria da Otimidade. Tese de doutorado, Porto Alegre, PUCRS, 2004.

Moreno, Cláudio. Os Diminutivos em -inho e -zinho e a Delimitação do Vocábulo Nominal no Português. Dissertação de mestrado, Porto Alegre, UFRGS, 1977.

Maurer Jr., Henrique. Um sufixo de Comportamento Original: o Diminutivo em -zinho. In: Raimundo Barbadinho Neto (org.). Estudos em Homenagem a Candido Jucá (filho). Rio de Janeiro: Simões, s/d, 233-46.

Nascentes, Antenor. O Idioma Nacional, $3^{\mathrm{a}} \mathrm{ed}$. Rio de Janeiro:Livraria Acadêmica, 1966.

Pereira, Eduardo Carlos. Gramática Expositiva. Curso Superior. São Paulo: Companhia Editora Nacional, 1955.

PotTIER, Bernard.Linguística moderna y Filologia Hispánica. Madrid: Gredos, 1968.

Ribeiro, João Grammatica Portugueza : Curso Superior. $16^{\mathrm{a}}$ ed. Rio de Janeiro: Francisco Alves, 1966, [1916].

Rocha Lima, Carlos Henrique. Gramática Normativa da Lingua Portuguesa. $15^{\text {a }}$ ed. Rio de Janeiro: José Olímpio, 1972.

SAId ALI, M. Gramática Histórica da Língua Portuguesa. São Paulo: Melhoramentos, 1964.

TAsca, Maria. A Lateral em Coda Silábica no Sul do País. Tese de Doutorado, Porto Alegre, PUCRS, 1999. 